\title{
Viscoelastic Behavior of Polyacrylonitrile/Dimethyl Sulfoxide Concentrated Solution with Water
}

\author{
WEIPING DU, ${ }^{1}$ HUIFANG CHEN, ${ }^{1}$ HAIFENG XU, ${ }^{1}$ DING PAN, ${ }^{1}$ NING PAN $^{2}$ \\ ${ }^{1}$ State Key Laboratory for Modification of Chemical Fibers and Polymer Materials, College of Material Science and \\ Engineering, Donghua University, Shanghai, People's Republic of China \\ ${ }^{2}$ Biological and Agricultural Engineering Department, University of California, California 95616
}

Received 24 December 2008; revised 29 April 2009; accepted 29 April 2009

DOI: 10.1002 / polb.21743

Published online in Wiley InterScience (www.interscience.wiley.com).

\begin{abstract}
The spinnability and polydispersity of polyacrylonitrile/dimethyl sulfoxide (PAN/DMSO $) / \mathrm{H}_{2} \mathrm{O}$ spinning solutions with conventional PAN molecular weight and comparative high PAN concentration have been investigated using a cone-plate rheometer. It is observed from the measurements that, the viscosities of the solutions decreased with the rising of shear rate, and then stabilized to almost the same value, regardless of the PAN concentration. The chain orientation in the fiber formed under constant shear rate cannot be changed considerably even after long relaxation of more than 900s. For dynamic experiments, a steady increase of both $G^{\prime}$ and $G^{\prime \prime}$ with escalating oscillation frequency was seen for all samples. Higher viscous-elastic modulus at higher $\mathrm{H}_{2} \mathrm{O}$ content was found, too. It is also concluded from the log $G^{\prime}-\log$ $G^{\prime \prime}$ plot and the gel point that the PAN/DMSO/ $\mathrm{H}_{2} \mathrm{O}$ system with regular PAN molecular weight behaves very close to a mono-disperse system, thus very suitable for gel spinning and for preparation of high performance PAN precursor fiber. (C) 2009 Wiley Periodicals, Inc. J Polym Sci Part B: Polym Phys 47: 1437-1442, 2009
\end{abstract}

Keywords: orientation; PAN; rheology; viscoelastic properties; water content

\section{INTRODUCTION}

Polyacrylonitrile (PAN)-based precursor fibers are widely known for producing high performance carbon fibers (compared to pitch, rayon, etc.) mainly because of its higher melting point and greater carbon yield ( $>50 \%$ of the original precursor mass). ${ }^{1-5}$ Conventional spinning processes for PAN precursor fiber include wet and dry-wet spinning, ${ }^{6,7}$ both with inherent disadvantages of uneven skin and core structure due to the phase separation process in the coagulation bath, hence greatly weakening the performance of the carbon

Correspondence to: W. Du (E-mail: h-wp@163.com)

Journal of Polymer Science: Part B: Polymer Physics, Vol. 47, 1437-1442 (2009) (๑) 2009 Wiley Periodicals, Inc. fiber. To avoid this skin and core disparity, gel spinning is introduced by doping nonsolvent into the PAN spinning solution and/or using a low processing temperature. ${ }^{8,9}$ Thus, the spinning solutions would change from a sol state to a gel state before the filament enters into the coagulation bath. Owing to the reduced mobility of the PAN chains, the evenness of the fiber structure resulted from mass transfer can be greatly improved, leading to eventually high performance carbon fibers. ${ }^{10}$

The structure, viscous flow and other properties of the spinning dope can be examined through its rheological behavior. ${ }^{11-16}$ Such rheological behavior can also be used to predict the extrusion performance of the spinning solution. So, rheology results can be used to prove whether the solution 
is suitable for spinning and to find better process conditions. ${ }^{17}$

PAN gel spinning with ultra high molecular weight and low concentration PAN has been studied. ${ }^{18}$ However, PAN with high molecular weight is difficult to dissolve to form a homogeneous solution, and the low PAN concentration is adverse to the mechanical properties of the fibers. In our early articles, ${ }^{19,20}$ the gelation process of PAN/dimethyl sulfoxide (DMSO) solutions (20 and 23\%) with or without water have been studied according to Winter and Chambon theory through dynamic methods. The gelation temperature, gel time, and the critical values of relaxation exponent $n$ were obtained by measuring the dynamic parameters $\left(G^{\prime}, G^{\prime \prime}, \tan \delta\right.$, and $\left.\eta^{*}\right)$ based on the Winter and Chambon theory. Although, in this article, solutions with regular molecular weight and comparatively high concentration PAN were proposed. The static and dynamic rheological behaviors of the PAN/DMSO solutions with $\mathrm{H}_{2} \mathrm{O}$ as the nonsolvent were investigated using a cone-plate rheometer. The relationships between the viscosity and shear rate, the chain orientation, the effects of temperature and $\mathrm{H}_{2} \mathrm{O}$ content on both $G^{\prime}$ and $G^{\prime \prime}$ were studied. The homogeneity and polydispersity of the system and their effects were also discussed.

\section{EXPERIMENTAL}

\section{Materials}

PAN copolymers (acrylonitrile: itaconic acid = 98:2 by weight) were provided by Shanghai Institute of Synthetic Fiber with a viscosity-average molecular weight about $7.8 \times 10^{4} \mathrm{~g} \mathrm{~mol}^{-1}$. Analytical grade DMSO was obtained from Boer chemical (Shanghai) Co. Ltd. Deionization water was used as nonsolvent without further treatment.

\section{Preparation of PAN/DMSO/ $\mathrm{H}_{2} \mathrm{O}$ Solutions}

All the experimental equipment and PAN materials were predried at $70{ }^{\circ} \mathrm{C}$ for $3 \mathrm{~h}$ for desiccation. The solvent used for the experiments was mixture of DMSO and the nonsolvent, $\mathrm{H}_{2} \mathrm{O}$. A given amount of PAN was first swelled statically in the mixed solvent at $55{ }^{\circ} \mathrm{C}$ for $4 \mathrm{~h}$, and stirred at 70 ${ }^{\circ} \mathrm{C}$ for another $4 \mathrm{~h}$ to ensure PAN dissolved evenly. The solutions were then deaerated in a vacuum drying oven at $70{ }^{\circ} \mathrm{C}$ for the removal of air bubbles and subsequently kept at this temperature for $24 \mathrm{~h}$ before the rheological experiments (this
Table 1. Concentration of PAN and $\mathrm{H}_{2} \mathrm{O}$ in Each Sample

\begin{tabular}{lrrrrrrr}
\hline Samples & S0 & S1 & S2 & S3 & S4 & S5 & S6 \\
\hline PAN (wt \%) & 20 & 20 & 20 & 20 & 20 & 23 & 25 \\
$\mathrm{H}_{2} \mathrm{O}($ wt \%) & 0 & 3 & 4 & 5 & 6 & 5 & 5 \\
\hline
\end{tabular}

operation is safe and the possible rheological change of the solutions is negligible). The concentration (weight percent wt \%) of each sample was listed in Table 1.

\section{Rheological Test}

The rheological measurements were conducted in a stress-controlled rheometer, RS150L (HAAKE, Germany) using the cone-plate geometry with the plate temperature controlled by a peltier unit. A sample cover provided with the instrument was used to minimize the change in sample composition due to evaporation during the measurement. The steady shear measurements were carried out by a stepwise programmation of the shear rate from 800 to $0 \mathrm{~s}^{-1}$. The storage modulus $G^{\prime}$ and loss modulus $G^{\prime \prime}$ as functions of frequency at a given temperature was conducted with frequency ranging from 0.01 to $100 \mathrm{~Hz}$. For the gel point experiments, the temperature dependence of the viscoelastic behavior were obtained from the frequency scanning data measured at various temperatures by a cooling procedure. Before the test at each temperature, all the samples were kept at that temperature for an adequate time period to eliminate the influence of the thermal history, and a new solution was chosen for each test to avoid the memory effects.

\section{RESULTS AND DISCUSSION}

\section{Static Rheological Measurements}

\section{Viscosity of PAN Solutions Under Shear Rate Scan}

Figure 1 shows the viscosity change of the PAN solutions of different concentration under various shear rates. At low shear rate range, a higher concentration leads to a greater viscosity, which decreases sharply with increasing shear rate until a critical level. Above this level, which seems to be independent of the concentration, the viscosity stabilizes regardless of either the shear rate or the concentration. This can be explained by shear alignment of the molecules and breaking of the 


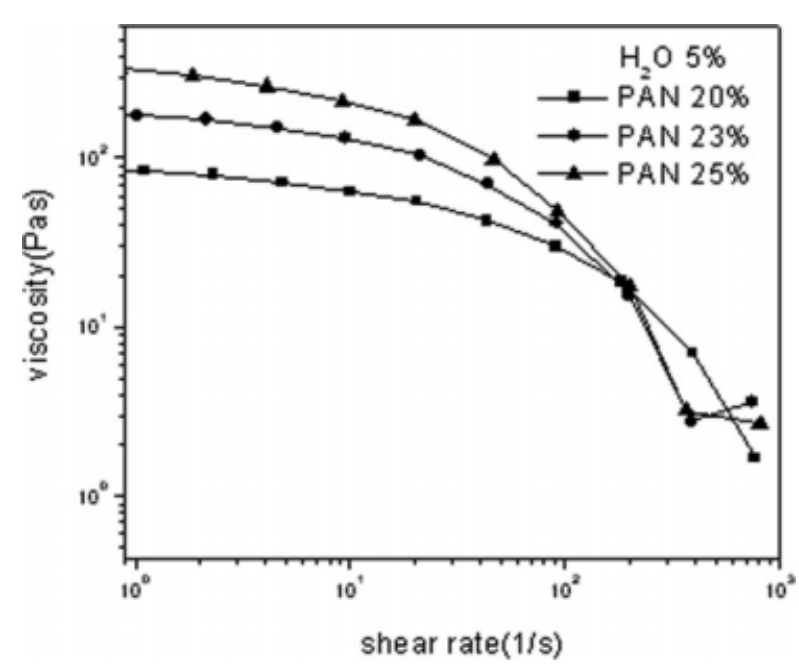

Figure 1. Viscosity of sample S3, S5, and S6 under shear rate scan. The PAN concentration is 20,23 , and $25 \%$, respectively. $\mathrm{H}_{2} \mathrm{O}$ content is $5 \%$.

entangled networks formed between the PAN molecules due to intermolecular van der Waals force, leading to the decrease of the viscosity before a critical shear rate. ${ }^{21,22}$ Such reorientation and disentanglement will complete once the shear rate reaching a critical level, and the viscosities of all the samples level off to almost the same value.

\section{Orientation Maintaining}

Whether the polymer solutions can maintain the aligned chain orientation once reached is very important for spinning process. The chain orientation in the solution determines the final orientation of the fibers. Therefore the viscosity of sample S6 $\left(25 \%\right.$ PAN and $\left.5 \% \mathrm{H}_{2} \mathrm{O}\right)$ was examined under shearing and relaxation conditions to check how well the orientation in the solution can be retained, as seen in Figure 2. In each experiment, a constant shear rate was applied for $300 \mathrm{~s}$, and then the shear action was stopped to let the solution relax for $0 \mathrm{~s}$ (first), $90 \mathrm{~s}$ (second) and $900 \mathrm{~s}$ (third), respectively. Similar to Figure 1, the flow curves decrease quickly and then level off. The starting viscosity of the second experiment after the first relaxation period $(90 \mathrm{~s})$ is almost the same as that before the relaxation. That means, after $90 \mathrm{~s}$, the achieved higher chain orientation, as reflected by a reduced viscosity, has not been lost significantly. That is to say, after the first waiting period, the orientation is held well. Even for the third experiment, the viscosity still has not recovered to the original value right after the shearing. That is, even after $900 \mathrm{~s}$, the chain ori- entation formed has not worsened significantly, a favorable discovery for fiber spinning.

\section{Dynamic Rheological Measurements}

\section{Temperature Effect on $G^{\prime}$ and $G^{\prime \prime}$}

Figure 3 shows the effect of temperature on $G^{\prime}$ and $G^{\prime \prime}$ against the frequency for sample S3 (20\% PAN and $5 \% \mathrm{H}_{2} \mathrm{O}$ ). As can be seen, a steady increase of both $G^{\prime}$ and $G^{\prime \prime}$ with oscillation frequency is observed at all four temperature levels. At a given testing frequency, a sample exhibits higher $G^{\prime}$ and $G^{\prime \prime}$ at lower temperatures, which is consistent with the phenomenon when no $\mathrm{H}_{2} \mathrm{O}$ added, ${ }^{19,20}$ reflecting the temperature sensitivity of both parameters.

\section{Homogeneity and Polydispersity}

The $\log G^{\prime}-\log G^{\prime \prime}$ plots have been widely applied to interpret the homogeneity and polydispersity of the polymer systems. ${ }^{23,24}$ This method was also applied in our system to retrieve information about the effect of miscibility on the visco-elastic behavior of the PAN systems. Figure 4 show the $\log G^{\prime}-\log G^{\prime \prime}$ plots for sample S3 (using the same data in Fig. 3). As known, for compatible and mono-disperse polymer blends, the $\log G^{\prime}-\log G^{\prime \prime}$ plot should be independent of both composition and temperature change. ${ }^{24}$ In Figure 4 , the 70 and $80{ }^{\circ} \mathrm{C}$ curves overlap well, and so do the 50 and $60{ }^{\circ} \mathrm{C}$ ones. This means the PAN dope at 70 and $80{ }^{\circ} \mathrm{C}$ essentially belongs to one state and at 50 and $60{ }^{\circ} \mathrm{C}$ to another state. Within each state, the curves become temperature

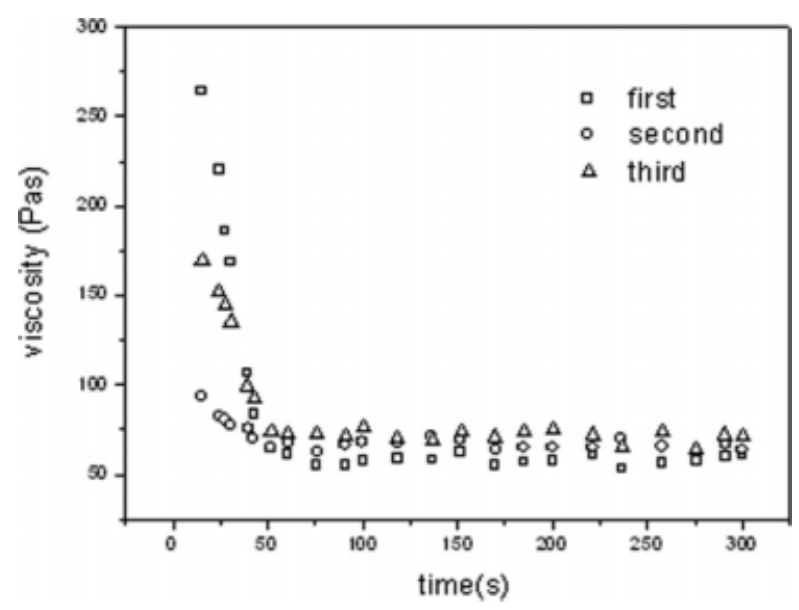

Figure 2. Viscosity change in cycles of applying and releasing shearing for Sample S6 (25\% PAN and 5\% $\mathrm{H}_{2} \mathrm{O}$ ). 

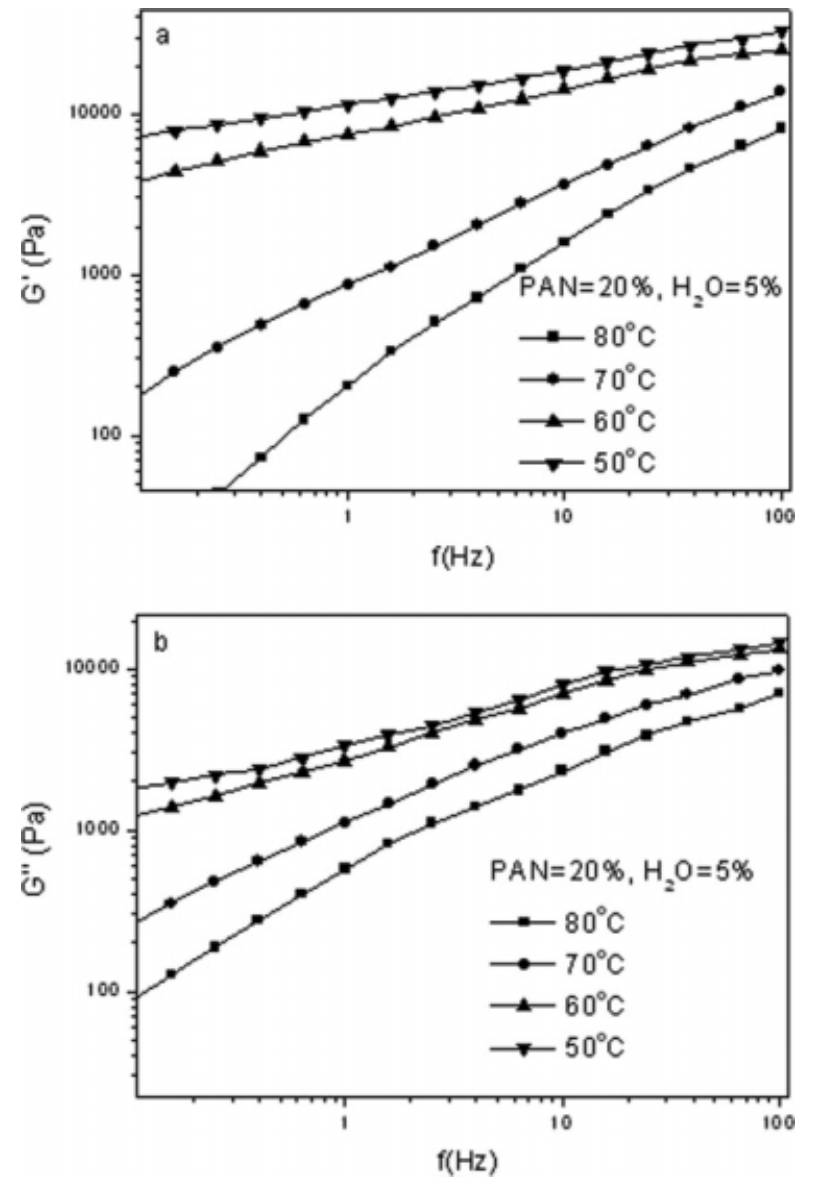

Figure 3. $G^{\prime}$ (a) and $G^{\prime \prime}$ (b) changes of sample S3 with increasing frequency at different temperatures. $\mathrm{PAN}=20 \%, \mathrm{H}_{2} \mathrm{O}=5 \%$.

independent. This temperature independence within each state can be attributed to the good miscibility and narrow dispersity of the systems. Yet the dope state changes over wider range of temperatures, that is $60-70{ }^{\circ} \mathrm{C}$, which is higher than the system that no $\mathrm{H}_{2} \mathrm{O}$ added. ${ }^{19}$

\section{Gel Point of Sample S3}

As we mentioned earlier, the state of the dope changes during $60-70{ }^{\circ} \mathrm{C}$, so it is necessary to determine the gel point of sample S3. As a common practice, many researchers use the crossover point of storage modulus $G^{\prime}$ and loss modulus $G^{\prime \prime}$ as the gel point, a simple and convenient method. ${ }^{25}$ In this article, we also used this criterion, as seen in Figure 5. It is obvious that the gel point temperature of sample S3 is about $62{ }^{\circ} \mathrm{C}$, which is higher than $45^{\circ} \mathrm{C}$, the gel point when no $\mathrm{H}_{2} \mathrm{O}$ was added. ${ }^{19}$ Combining Figures 4 and 5, a conclusion can be made that 50 and $60{ }^{\circ} \mathrm{C}$ corre-

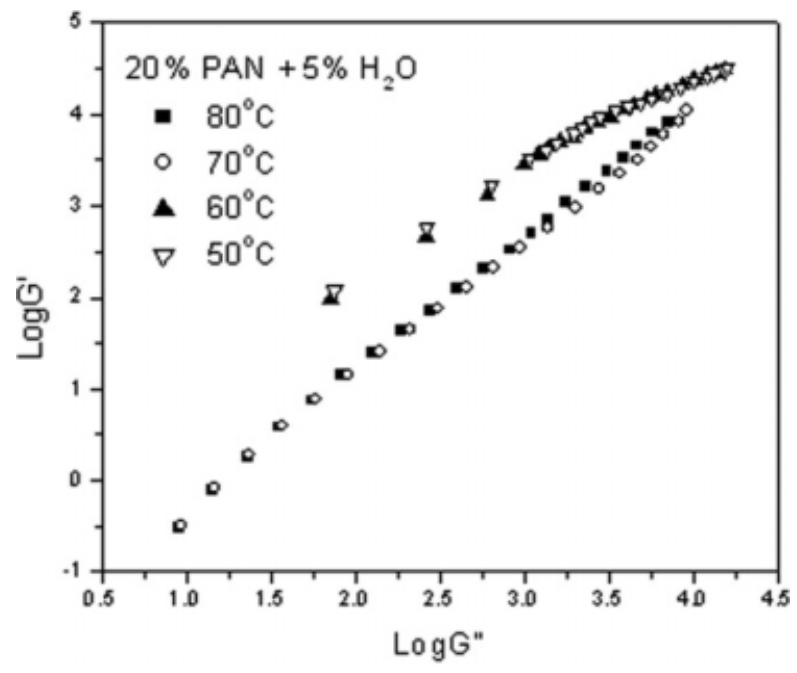

Figure 4. Logarithmic relationship between $G^{\prime}$ and $G^{\prime \prime}$ of sample S3 at different temperatures. PAN = $20 \%, \mathrm{H}_{2} \mathrm{O}=5 \%$.

spond to the gel state and 70 and $80{ }^{\circ} \mathrm{C}$ to the solution state. Then $60-70{ }^{\circ} \mathrm{C}$ lay within the sol-gel transition range.

\section{$\mathrm{H}_{2} \mathrm{O}$ Effect on the Viscoelasticity of PAN Solutions}

The effect of nonsolvent, $\mathrm{H}_{2} \mathrm{O}$, on the viscoelasticity of PAN solutions under different frequency has also been examined as shown in Figure 6 . Both $G^{\prime}$ and $G^{\prime \prime}$ increase with the oscillation frequency for $\mathrm{H}_{2} \mathrm{O}$ content involved, and a sample with higher $\mathrm{H}_{2} \mathrm{O}$ content exhibits greater $G^{\prime}$ and $G^{\prime \prime}$ values, showing the modulus sensitivity to $\mathrm{H}_{2} \mathrm{O}$ content in the PAN solutions.

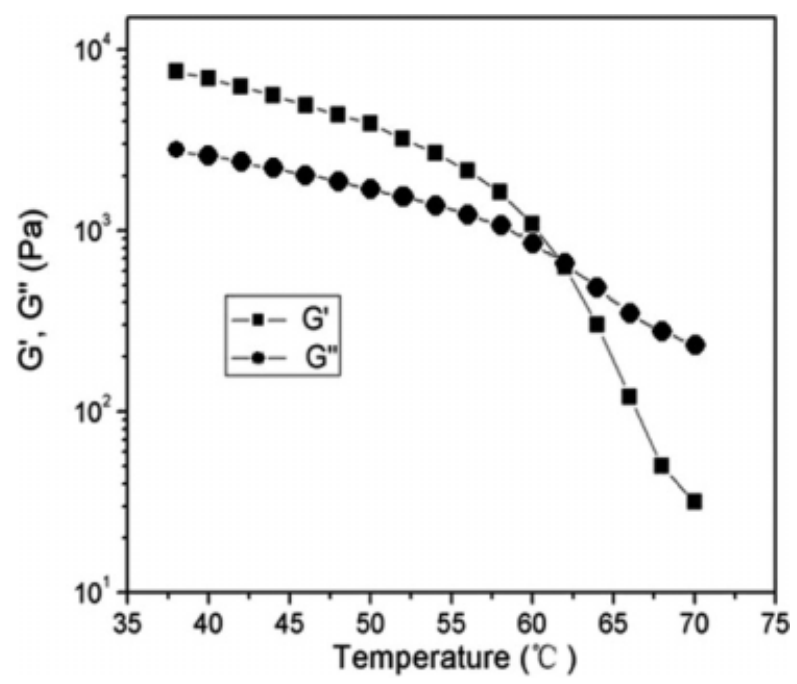

Figure 5. $G^{\prime}$ and $G^{\prime \prime}$ of sample $\mathrm{S} 3$ as a function of temperature. $\mathrm{PAN}=20 \%, \mathrm{H}_{2} \mathrm{O}=5 \%$.

Journal of Polymer Science: Part B: Polymer Physics DOI $10.1002 /$ polb 

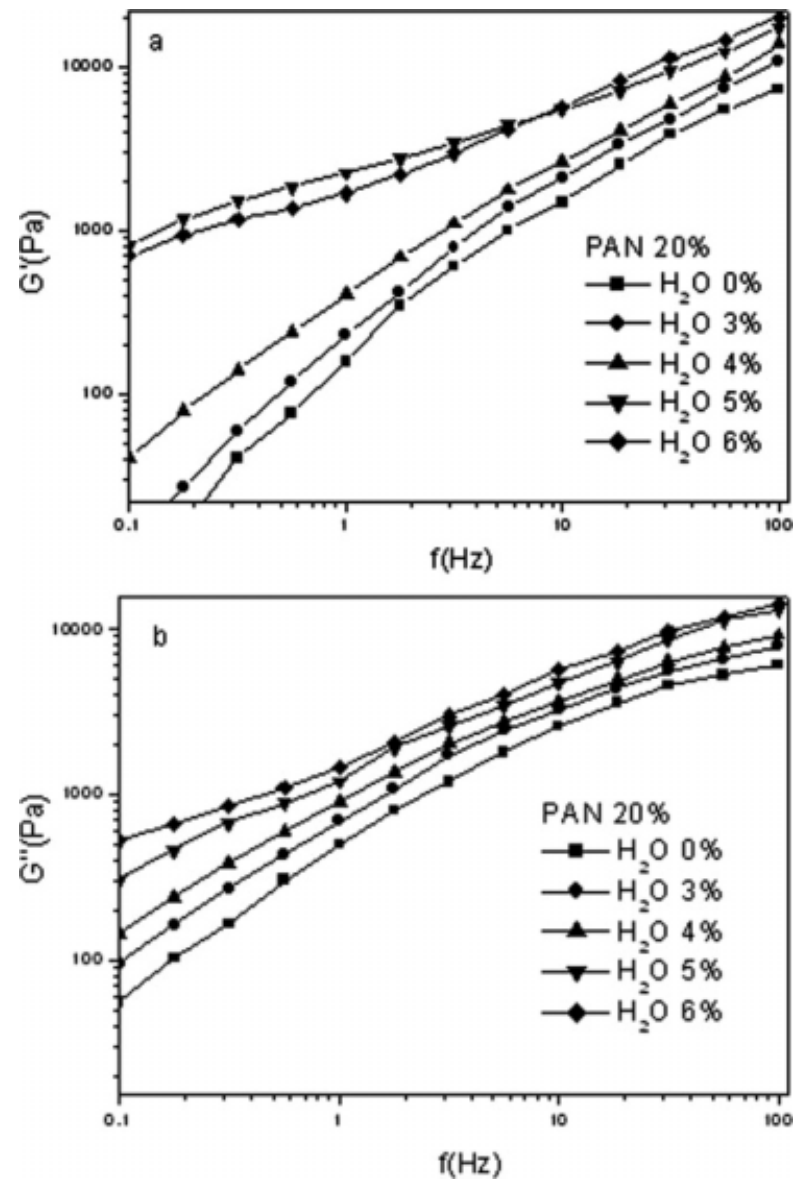

Figure 6. $G^{\prime}$ (a) and $G^{\prime \prime}$ (b) changes of sample S0, $\mathrm{S} 1, \mathrm{~S} 2, \mathrm{~S} 3$, and $\mathrm{S} 4$ with increasing frequency at $70^{\circ} \mathrm{C}$. $\mathrm{PAN}=20 \%, \mathrm{H}_{2} \mathrm{O}=0,3,4,5$, and $6 \%$, respectively.

\section{$\log G^{\prime}-\log G^{\prime \prime}$ Plots of PAN Solutions with Different $\mathrm{H}_{2} \mathrm{O}$ Content}

We also used the $\log G^{\prime}-\log G^{\prime \prime}$ plot to study the homogeneity and polydispersity of $20 \%$ PAN solutions with different $\mathrm{H}_{2} \mathrm{O}$ content at $70{ }^{\circ} \mathrm{C}$, illustrated in Figure 7 (with the same data from Fig. 6). All the curves with different $\mathrm{H}_{2} \mathrm{O}$ content at $70{ }^{\circ} \mathrm{C}$ coincide with one another well, indicating that all these solutions fall into the same state, owing to the good miscibility and narrow dispersity. The gel point of the sample $\mathrm{S} 4\left(6 \% \mathrm{H}_{2} \mathrm{O}\right)$ was also determined in Figure 8. It can be seen that the gel point of $\mathrm{S} 4$ sample is about $67^{\circ} \mathrm{C}$, so the sample $\mathrm{S} 4$ with lowest $\mathrm{H}_{2} \mathrm{O}$ content will be at solution state now $T=70{ }^{\circ} \mathrm{C}$. Considering the fact that solutions with higher nonsolvent content possess higher gel points when other conditions are constant, all the samples S0, S1, S2, S3, and S4 in Figure 6 should be at solution state, and thus no sol-gel transition occurs at $70^{\circ} \mathrm{C}$.

Journal of Polymer Science: Part B: Polymer Physics DOI $10.1002 /$ polb

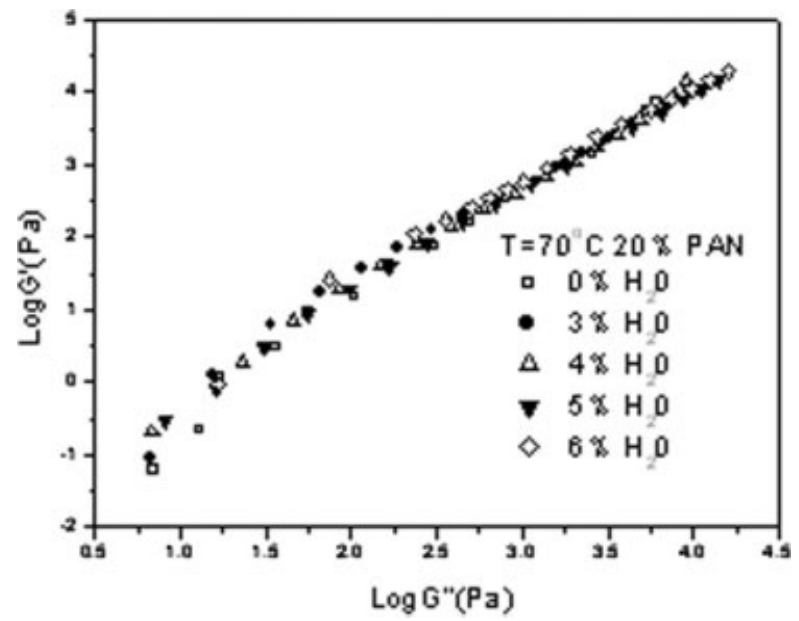

Figure 7. Logarithmic relationship between $G^{\prime}$ and $G^{\prime \prime}$ of sample S0, S1, S2, S3, and S4 at $70{ }^{\circ} \mathrm{C}$. PAN = $20 \%, \mathrm{H}_{2} \mathrm{O}=0,3,4,5$, and $6 \%$, respectively.

\section{Theoretical Interpretation of $\log G^{\prime}$ Versus $\log G^{\prime \prime}$}

By definition, the state change takes place over the gel point. Right at the gel point however, the samples can be in any of the three states: solution state, sol-gel state and gel state, respectively. In Figures 4 and 7, all the curves at either solution state or the gel state have the slope around 1, which could be explained through Doi-Edwards theory. ${ }^{24}$

$$
\log G^{\prime}=n \log G^{\prime \prime}-\log c T+\log \left(M_{e}\right)
$$

where $c$ is a material constant, $T$ the absolute temperature, $M_{e}$ the average molecular weight

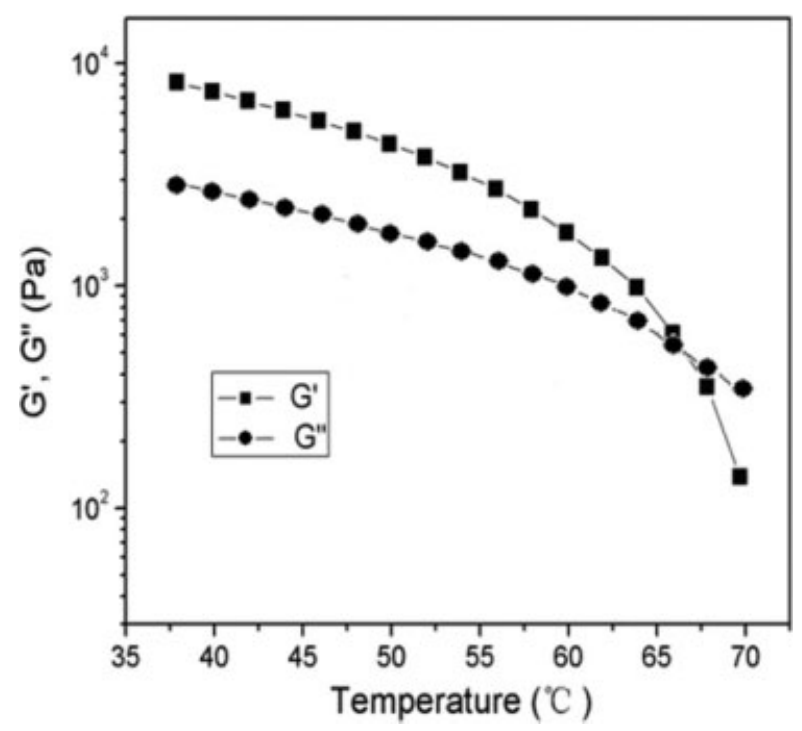

Figure 8. $G^{\prime}$ and $G^{\prime \prime}$ of sample $\mathrm{S} 4$ as a function of temperature. $\mathrm{PAN}=20 \%, \mathrm{H}_{2} \mathrm{O}=6 \%$. 
between the entanglement points, and $n$ the slope of a $\log G^{\prime}-\log G^{\prime \prime}$ plot.

For common systems, $n=2$, whereas for a perfectly compatible and mono-disperse system, $n=$ 1 , and the value exceeding two is the evidence of polydispersity. In our study, the slopes of the $\log G^{\prime}-\log G^{\prime \prime}$ plots in Figures 4 and 7 are about 1 , revealing that the PAN solutions with regular low molecular weight used in this study, whether containing $\mathrm{H}_{2} \mathrm{O}$ or not, behave very close to a mono-disperse system. That is to say, the PAN solutions, with conventional PAN molecular weight and relatively high PAN concentration, are suitable for gel spinning.

\section{CONCLUSIONS}

PAN/DMSO/ $\mathrm{H}_{2} \mathrm{O}$ systems, with relatively high PAN concentration of regular molecular weight, have been investigated under static and dynamic conditions using rheological methods.

1. The viscosities of the solutions decreased with the rising of shear rate, and then leveled off to almost the same value, regardless of the PAN concentration. This is due to the shear alignment of the molecular chains and breaking of the entangled networks, and once the orientation has been completed under a sufficient shear condition, the viscosity does not change anymore under further shearing.

2. The PAN system used in our work can hold this chain orientation formed under the shear rate, favorable to the fiber spinning process.

3. $G^{\prime}$ and $G^{\prime \prime}$ steadily increase with oscillation frequency, and lower temperature and/or higher $\mathrm{H}_{2} \mathrm{O}$ content lead to greater $G^{\prime}$ and $G^{\prime \prime}$ values.

4. For systems with $20 \% \mathrm{PAN}$ and $5 \% \mathrm{H}_{2} \mathrm{O}$, the 70 and $80{ }^{\circ} \mathrm{C}$ curves overlap well, indicating both are at the solution state. Similarly 50 and $60{ }^{\circ} \mathrm{C}$ curves belong to the gel state. Within each state, the curves become temperature independent, attributed to the good miscibility and narrow dispersity of the systems.

Resulted from the theoretical study, the PAN systems with conventional PAN molecular weight is close to mono-disperse systems, which are very suitable for gel spinning.

This work was supported by grants from the National Basic Research Program (973 Program) (2006CB
605303), Shanghai Leading Academic Discipline Project (B603), the Shanghai Fundamental Theory Program (07DJ14002), National Natural Foundation of China (50333050) and the Program of Introducing Talents of Discipline to Universities (No. 111-2-04).

\section{REFERENCES AND NOTES}

1. Bahl, O. P.; Manocha, L. M. Carbon 1974, 12, 417-423.

2. Bahl, O. P.; Mathur, R. B. Fiber Sci Technol 1979, 12, 31-37.

3. Barham, P. J.; Hill, M. J.; Keller, A. Colloid Polym Sci 1980, 258, 899-908.

4. Gupta, A. K.; Paliwal, D. K.; Bajaj, P. JMS-REV Macromol Chem Phys 1991, C31, 1-89.

5. Kikutani, T. J Appl Polym Sci 2002, 83, 559-571.

6. Vuković, J.; Lechner, M. D.; Jovanović, S. Macromol Chem Phys 2007, 208, 2321-2330.

7. Chen, H.; Ying, L. J Appl Polym Sci 2006, 100, 3377-3381.

8. Nagashima, N.; Matsuzawa, S.; Okazaki, M. J Appl Polym Sci 1996, 62, 1551-1560.

9. Wang, Z.; Xu, Z.; Wan, L. J Membr Sci 2006, 278, 447456.

10. Zhang, W.; Liu, J.; Wu, G. Carbon 2003, 41, 28052812.

11. Devasia, R.; Reghunadhan, C. P.; Ninan, K. N. Polym Int 2005, 54, 381-385.

12. Zhao, X.; Stylios, G. K.; Christie, R. M. J Appl Polym Sci 2008, 107, 2317-2321.

13. Ansarifar, M. A.; Luckham, R. F. Colloid Polym Sci 1989, 267, 736-740.

14. Fujiyama, M.; Kondou, M. J Appl Polym Sci 2003, 90, 1808-1824.

15. Wang, B.; Li, J.; Wang, H.; Jiang, J.; Liu, Y. Macromol Symp 2004, 216, 189-194.

16. Liu, W.; Cheng, L.; Zhang, H.; Zhang, Y.; Wang, H.; Yu, M. Int J Mol Sci 2007, 8, 180-188.

17. Schramm, G. A Practical Approach Rheology and Rheometry; Gebrueder HAAKE Gmbh: Karlsruhe, Germany, 1994.

18. Qian, B. J.; Lin, W. P.; He, J. M.; Hu, P. P.; Wu, C. X. J Polym Eng 1995, 15, 327-335.

19. Tan, L. J.; Liu, S. P.; Pan, D. J Phys Chem B 2009, 113, 603-609.

20. Tan, L. J.; Pan, D.; Pan, N. Polymer 2008, 49, 56765682.

21. Rehage, H.; Hoffmann, H. J Phys Chem 1988, 92, 4712-4718.

22. Chiu, H.; Wang, J. J Appl Polym Sci 1998, 70, 1009_ 1016.

23. Ohta, Y.; Murase, H.; Sugiyama, H.; Yasuda, H. Polym Eng Sci 2000, 40, 2414-2422.

24. Han, C. D.; John, M. S. J Appl Polym Sci 1986, 32, 3809-3840.

25. Chanbon, F.; Winter, H. H. J Rheol 1987, 31, 683697.

Journal of Polymer Science: Part B: Polymer Physics DOI $10.1002 /$ polb 